\title{
Astronomical forcing of sedimentary cycles in the middle to late Miocene continental Calatayud Basin (NE Spain)
}

\author{
H. Abdul Aziz ${ }^{a}, *$ F. Hilgen ${ }^{a}$, W. Krijgsman ${ }^{b}$, E. Sanz ${ }^{c}$, J.P. Calvo ${ }^{\text {d }}$ \\ a Department of Geology, Faculty of Earth Sciences, Utrecht University, Budapestlaan 4, 3584 CD Utrecht, The Netherlands \\ b Paleomagnetic Laboratory 'Fort Hoofddijk', Utrecht University, Budapestlaan 14, 3584 CD Utrecht, The Netherlands \\ c Centro de Astrobiología (INTA-CSIC), Crta. de Ajalvir s/n, 28850 Torrejón de Ardoz, Madrid, Spain \\ d Departemento de Petrologia y Geoquímica, Fac. CC. Geológicas, Universidad Complutense, 28040 Madrid, Spain
}

Received 16 August 1999; received in revised form 28 January 2000; accepted 29 January 2000

\begin{abstract}
A high-resolution cyclostratigraphic and magnetostratigraphic study was carried out on cyclically bedded successions of middle Miocene lacustrine to distal alluvial fan-floodplain deposits from the Calatayud basin, in northeast Spain. Eight (partially overlapping) subsections near the village of Orera are correlated in detail using distinct sedimentary cycle patterns or by following marker beds in the field. Together they form the Orera Composite Section (OCS). Sedimentary cycles are recognised on at least two different scales. The basic small-scale cycles in the OCS consist of an alternation of grey and, occasionally, red clays with white, dolomite-rich, carbonate beds. They are arranged in largerscaled, so-called large-scale cycles based on repetitive changes in the overall carbonate-clay lithology. Two other, but less distinct, types of intermediate scale cyclicity are also recognised. In terms of depositional environment, the cycle hierarchy is interpreted to represent periodic lake expansion over the palaeo-alluvial fan-floodplain area. The palaeomagnetic results yield a reliable magnetostratigraphic record, which confirms the cyclostratigraphic correlations between the subsections in detail. Rock magnetic experiments reveal that haematite is the main magnetic carrier of the primary component. The magnetostratigraphy of the OCS is correlated straightforwardly with the geomagnetic polarity time scale. This resulted in an age of 10.7-12.8 Ma for the entire succession, which is supported by fossil micromammal findings. In addition, it also reveals the presence of two, possibly three, short new polarity intervals. Based on the number of cycles in the OCS the average periodicity of the basic small-scale cycles is approximately $23000 \mathrm{yr}$, while the large-scale cycle indicates a periodicity of $400000 \mathrm{yr}$. This suggests that these sedimentary cycles are controlled by astronomically induced climate changes causing lake-level fluctuations and thus resulting in the deposition of carbonate-clay cycles. The continental sequences of the OCS provide a unique opportunity to extend the astronomical polarity time scale into the middle Miocene. The overlap of such continental sequences in the Mediterranean area with time-equivalent astronomically induced marine sequences is fundamental for establishing marine-continental, bed-tobed, correlations and for understanding regional climate change. (C) 2000 Elsevier Science B.V. All rights reserved.
\end{abstract}

Keywords: terrestrial sedimentation; Miocene; cyclic processes; magnetostratigraphy; climate change

\footnotetext{
* Corresponding author. Tel.: +31-30-253-5125; Fax: +31-30-253-5030; E-mail: haziz@geo.uu.nl
} 


\section{Introduction}

Time control in the continental record is often poor compared to the excellent time control in the marine record which has been achieved by calibrating sedimentary cycles and other cyclic variations to computed time series of the Earth's orbital parameters or to derived target curves. The resultant astronomical (polarity) time scales (A(P)TS) with a resolution and an accuracy of several thousand years have now been firmly established for the entire Pliocene-Pleistocene [1-4] and have already been extended into the middle Miocene [5-7]. These time scales are now used for climate studies [8]. For a comprehensive understanding of the Earth's climate in the past it is fundamental to include the continental record in an astronomically dated time stratigraphic framework. In fact, continental settings are expected to register orbitally induced climate changes more directly because they are not influenced by complex oceanographic processes which include linear and non-linear feed-back mechanisms.

Until now, the role of astronomically induced climate variations in the deposition of sedimentary cycles in continental settings has often been underestimated; they are often linked to autocyclic processes such as tectonics and base-level change. Nevertheless, allocyclicity has been inferred for continental settings where subsidence is balanced by sedimentation. Already in 1929, Bradley [9] suggested that varves and sedimentary cycles in the Eocene Green River Formation are climatically linked and astronomically controlled. Orbital forcing has been demonstrated for the Triassic successions of the Newark Basin [1012]. Both successions are (fluvio-)lacustrine and contain sedimentary cycles of different scales which are related to lake-level fluctuations induced by climate change.

Long and continuous continental successions, with a direct and accurate time control, are present in the Mediterranean area. Krijgsman et al. [13] demonstrated that prominent limestone beds (caliches) in Miocene red bed sequences of the Calatayud basin in Spain are related to the $100000 \mathrm{yr}$ eccentricity cycle, while less distinct small-scale cycles are probably precession-con- trolled [14]. Recent studies indicate that cyclic lacustrine lignite-marl alternations in the Ptolemais basin in northern Greece also reflect precessioncontrolled variations in local climate $[15,16]$. The presence of these successions close to time-equivalent cyclically bedded marine successions is of great importance for establishing continental-marine bed-to-bed correlations and for understanding the influence of astronomically induced climate oscillations in the circum-Mediterranean region.

In this paper we present the detailed results of an integrated high-resolution cyclostratigraphic and magnetostratigraphic study of lacustrine and distal alluvial fan-floodplain deposits near the village of Orera in the Calatayud basin. These middle Miocene deposits display an extraordinary cyclic alternation of clays and carbonate beds on different scales. Our aim is to demonstrate the presence of a hierarchy in the sedimentary cycle patterns and to interpret them in terms of climate change. For this purpose we constructed a composite section on the basis of the magnetostratigraphic and cyclostratigraphic correlations of overlapping parts of individual subsections. Correlation of the magnetostratigraphy of our composite section to the geomagnetic polarity time scale (GPTS) will provide a first-order age control necessary for demonstrating an allocyclic origin of the sedimentary cyclicity.

\section{Geological setting and stratigraphy}

The studied succession was deposited in the Calatayud Basin, an elongated intermontane basin located within the NW-SE trending Iberian Range. The graben-like structure of the basin resulted from extensional processes that were initiated during the Oligocene-Miocene transition and continued throughout the Neogene [17]. The basin is flanked by Palaeozoic rocks and bounded by NW-SE trending normal faults, which steeply dip towards the basin centre [18]. The basin fill comprises a $1200 \mathrm{~m}$ thick sedimentary succession [19] of lacustrine and alluvial fan-floodplain sediments, which can be divided into three units $[20,21]$. The study area comprises sediments 


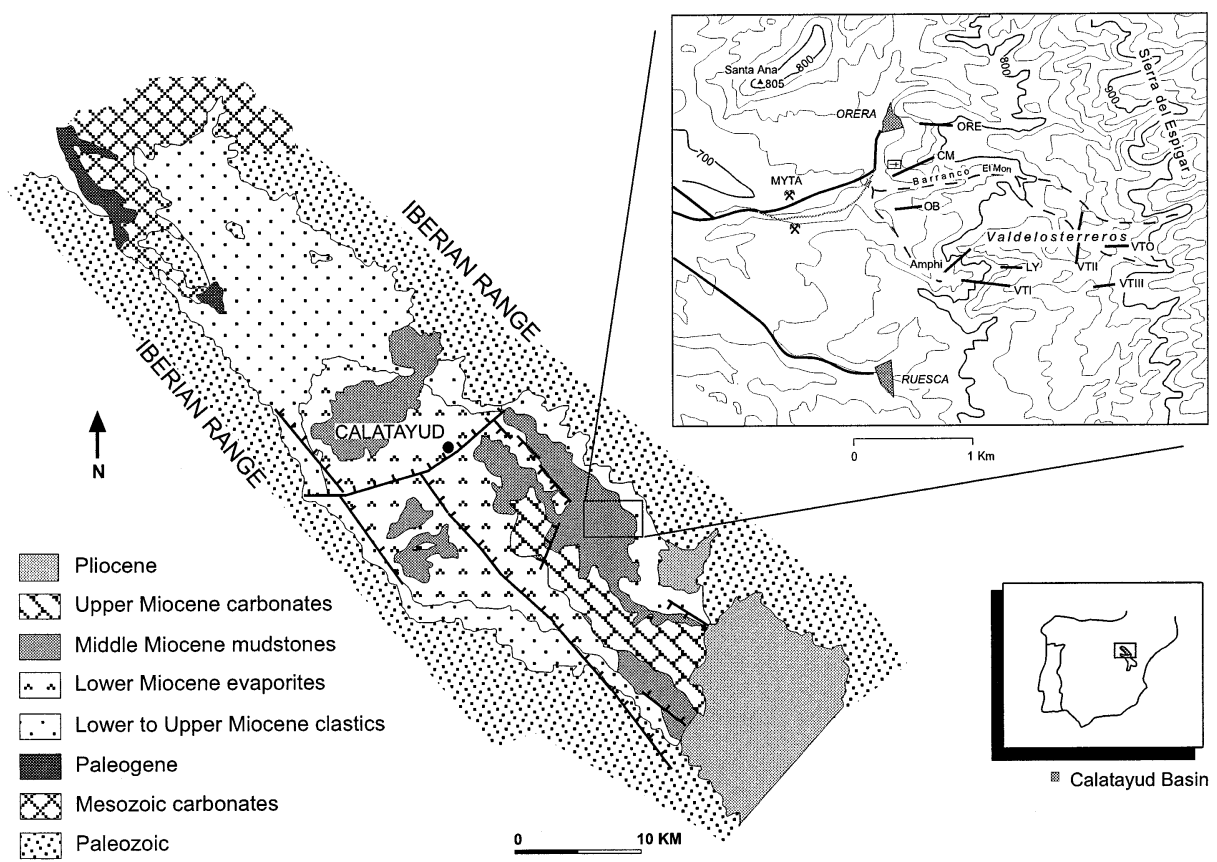

Fig. 1. Location map of the study area and of the subsections in the Calatayud Basin.

from the Intermediate unit, which are of Agenian to Turolian age (10-25 Ma) [21]. The sediments display a concentric facies distribution pattern with coarse-grained alluvial fan successions along the basin margin, progressively passing via distal alluvial fan-floodplain deposits into palustrine, lacustrine sediments and finally into evaporites in the centre of the basin (Fig. 1). Locally, coarse alluvial fan deposits of Pliocene and Quaternary age unconformably overlie these Miocene deposits.

The study area is located $10 \mathrm{~km}$ southeast of Calatayud in the vicinity of the villages of Orera and Ruesca (Fig. 1). In this area, a marked cyclically bedded succession of lacustrine and distal alluvial fan-floodplain deposits is present, characterised by grey, occasionally red, clays and dolomitic marls alternating with white carbonates. Geometrical relationships between the cyclical succession and the alluvial fans deposits indicate that the cyclic sediments were deposited in a topographic low (shallow lake) which formed in a 'shadow zone' between the alluvial fans.

Sedimentary cyclicity is not restricted to this study area but is also observed in other facies of the Calatayud basin such as basinal evaporites [20] and in (groundwater) caliches intercalated in red-bed sequences [14]. Although lateral facies changes do occur in the study area we conclude that the sedimentary cyclicity is a basin-wide feature and not a local phenomenon affected by lateral facies migration.

Considering the lateral facies changes and the vertical restriction of the cyclical sedimentary facies to the same palaeogeographical area, it is likely that subsidence was essentially balanced by sedimentation. This created a favourable condition for the formation of climate-induced sedimentary cyclicity despite the limited palaeogeographical extent of the area.

\section{Cyclostratigraphy}

A total of eight, partially overlapping, subsections were selected on the basis of their sedimentary cycle patterns in principally the same (alternation of) sedimentary facies. The subsections 
Orera Base (OB), Cementerio (CM), Orera Village (ORE), Valdelosterreros I, II and III (VT-I, VT-II and VT-III), Valdelosterreros Overlap (VTO) and LY (see Figs. 1 and 2) were logged in detail and together provide a continuous record. Correlations between subsections were established by tracing specific beds in the field. Where direct correlations between subsections were hampered by a lack of exposures, correlations were achieved by matching characteristics in the sedimentary cycle patterns. For this purpose, subsections were logged with a considerable overlap.

A sedimentary cycle consists of a carbonate bed and red (reddish brown) or grey clay. Carbonate beds vary in thickness between 0.15 and $1 \mathrm{~m}$. They are mainly dolomitic and often appear as soft, and sometimes laminated, massive beds. Carbonate beds may also appear as relatively thin and/or vaguely developed beds or may contain densely packed rhizoliths. The red and reddish brown clay ranges in thickness from a few decimetres up to $2 \mathrm{~m}$. Clay mineral fractions dominate though the silt- to sand-sized fraction increases in the red units of the more proximal subsections. Bioturbation by rootletting is sparse. In contrast, the grey clays often contain abundant rootlets. The thickness of the grey clay is approximately $1-1.5 \mathrm{~m}$ and often overlies a red or reddish brown clay unit. The clay mineral content is relatively high and the silt- to sand-sized fraction is relatively low compared to the red clay.

We define the carbonate beds as the base of a sedimentary cycle; they are numbered in ascending order from the base of the stratigraphically lowermost subsection OB to the top of the youngest subsection VT-III. Faintly developed carbonate beds, which may represent an extra cycle, are assigned an ' $A$ ' number of the preceding cycle. These cycles are referred to as potential extra cycles in the description below.

Lateral facies changes tend to obscure the typical cyclical patterns but have been avoided by selecting subsections with the most prominent sedimentary cycles. Nevertheless, lateral changes are present and, where necessary, have been included in the description and interpretation of the cyclostratigraphy.

In the following sections we will present a brief description of the cyclostratigraphy of the individual subsections starting from the base. For the detailed description we refer to the EPSL Online Background Dataset ${ }^{1}$.

\subsection{Orera base $(O B)$}

Subsection OB contains cycles 1-10 and two potential extra cycles $6 \mathrm{~A}$ and 9A (Fig. 2). Two distinct intervals can be recognised. The lower red to brown coloured interval (cycles 1-4) is clay-rich with thin and indistinct carbonate beds while the upper interval (cycles 6-10) is grey coloured showing regular and well-developed carbonate beds. The average cycle thickness is $1.6 \mathrm{~m}$.

\subsection{Cementerio $(C M)$}

Subsection Cementerio (CM) contains cycles 318 and potential extra cycles 13A, 15A, 16A and 18A (Fig. 2). Direct, physical tracing of the beds from $\mathrm{OB}$ to $\mathrm{CM}$ proved impossible due to lack of exposure, despite the fact that the distance between both subsections is less than $200 \mathrm{~m}$. Therefore, the stratigraphic connection is based on characteristic patterns (of cycles 4-8) in combination with bedding-plane orientation and the (inferred) absence of faults.

Subsection CM consists of three distinct intervals. The lower interval comprises regularly developed cycles 5-12 with distinct carbonate beds. It is followed by a darker, brownish to red coloured interval (cycles 13-15) in which cycles are not well developed and carbonate beds are less distinct. As a consequence, several ' $A$ ' cycles are recognised in this part. The upper interval again shows a regular and well-developed sedimentary cyclicity with distinct carbonate beds alternating with grey clays. The average cycle thickness of about 1.7 $\mathrm{m}$ is reduced to $1.55 \mathrm{~m}$ when the ' $\mathrm{A}$ ' cycles are included. Lateral changes in the thickness of carbonate beds between subsections $\mathrm{OB}$ and $\mathrm{CM}$ occur but do not obscure the characteristic cyclic pattern. For example, the well-developed carbo-

\footnotetext{
1 http://www.elsevier.nl/locate/epsl; mirror site: http://www. elsevier.com/locate/epsl
} 

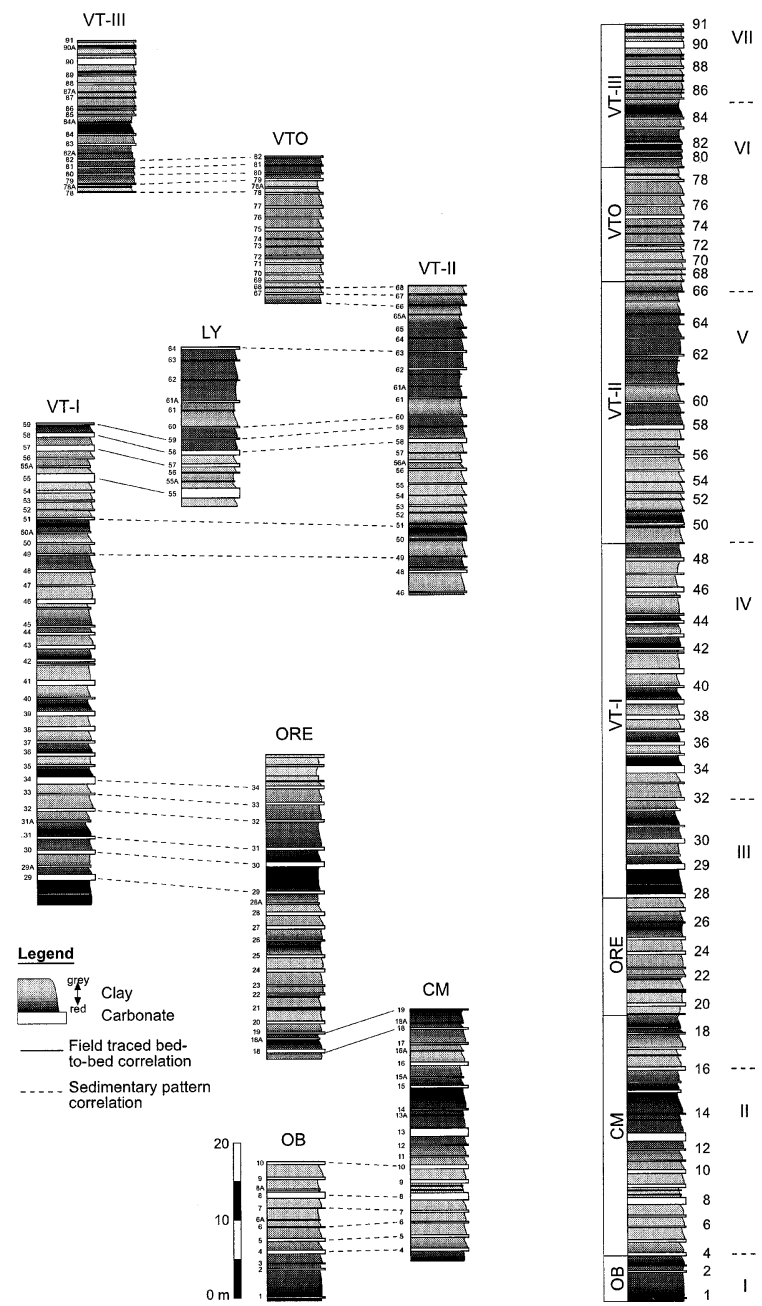

Fig. 2. Cyclostratigraphic correlations between subsections and construction of the Orera Composite Section (OCS). Continuous intervals of subsections comprising the most prominent and ideal developed cyclicity are selected for the OCS and are represented next to the lithological column of the OCS. No scaling corrections have been applied. Numbers along lithological columns correspond to sedimentary cycles as described in the text. Roman numbers along OCS column indicate the large-scale cycles of alternating carbonate-rich intervals with distinct basic small-scale cycles and carbonatepoor (clay-rich) intervals with thick and indistinct basic small-scale cycles.

nate bed of cycle 5 in $\mathrm{OB}$ is less distinct in $\mathrm{CM}$, while cycle $6 \mathrm{~A}$ is only developed in OB. Generally, the single and massive carbonate beds of subsection $\mathrm{OB}$ tend to split into numerous thin beds in $\mathrm{CM}$.

\subsection{Orera village (ORE)}

Subsection ORE contains cycles 18-34 and two potential extra cycles, 18A and 28A (Fig. 2). The stratigraphic connection between subsections ORE and CM was achieved by (physical) tracing of cycles 18 and 19 (including successive cycles) from CM to ORE.

Two intervals can be distinguished in subsection ORE. The lower interval, comprising cycles $18-27$, is characterised by regular cycles often with distinct, thick carbonate beds that split up into thinner beds. The upper interval (cycles 2834 ) is dominated by reddish coloured clays in which cycles are poorly developed and carbonate beds are less pronounced, or even absent.

The yellow uppermost part of ORE (from cycle 34 upward) consists of a gravel bed and silty to sandy layers with intercalated caliches. At the top a thick carbonate-rich bed with typical channel morphology occurs. Altogether, this type of facies has not been recognised elsewhere in the sections studied and we therefore are cautious about interpreting the cyclostratigraphy of this uppermost part of the subsection.

\subsection{Valdelosterreros I (VT-I)}

Subsection VT-I contains cycles 29-59 and four potential extra cycles 29A, 31A, 50A and 55A (Fig. 2). Within VT-I four distinct intervals can be distinguished. The lower interval comprises cycles 29-32 characterised by thick developed cycles with reddish to brown coloured clays and weakly developed carbonate beds. The next interval (cycles 33-40) shows a very regular cyclicity with distinct carbonate beds (Fig. 3A). The third interval (cycles 41-51) is characterised by the recurrence of poorly developed and more clay-rich cycles often with less distinct and double developed carbonate beds. Finally, in the fourth and uppermost interval (cycles 51-59), the cycles are regular and distinct again and are accompanied by a marked increase in thickness of the carbonate beds.

Distinct features of this subsection are the red clays of cycles 45 and 48 but the most striking is the conspicuous red coloured silt of cycle 50. This 


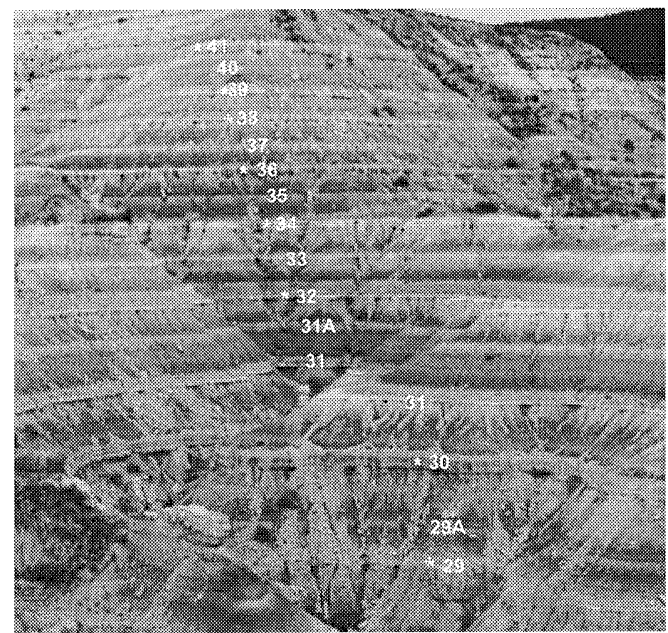

(A)

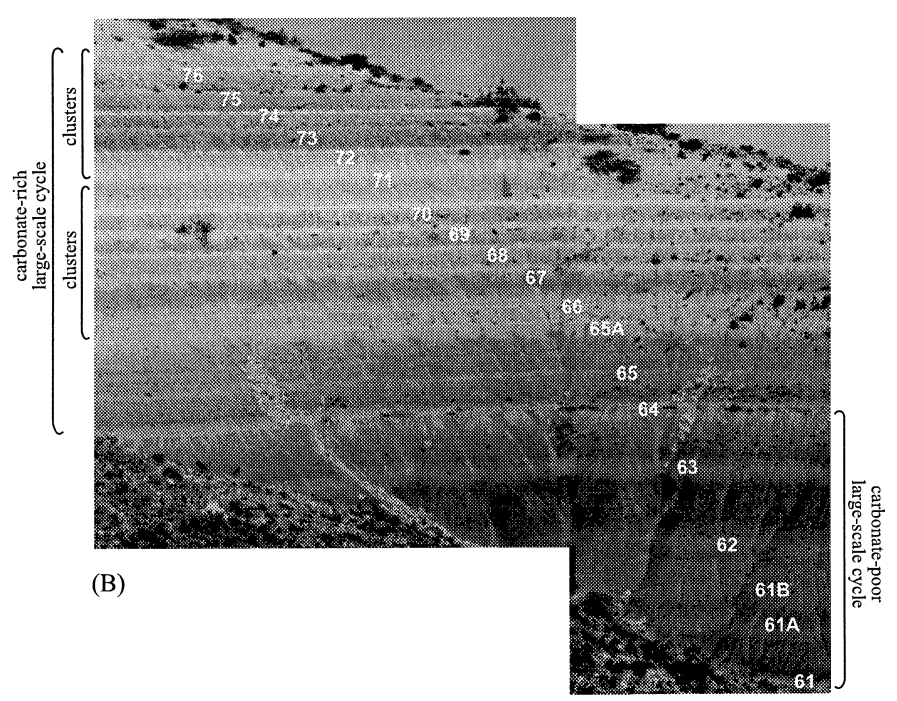

Fig. 3. (A) Photograph of the lower part of VT-I showing the basic small-scale, carbonate-clay alternation cycles and the alternations of thin and thick carbonate beds (thick beds are marked with an asterisk). (B) Photograph of the upper part of VT-II showing the large-scale cycles. The carbonate-poor interval is recognised between cycles 61 and 65 while in the carbonate-rich interval (between cycles 65 and 77), bundles of five and six cycles occur, as can be seen in 66-70 and 72-77.

bed can be easily recognised throughout the study area.

\subsection{Overlap $L Y$}

The short subsection LY comprises cycles 5564 and two potential extra cycles 55A and 61A (Fig. 2). Correlation between subsections LY and VT-I is straightforward and based on (physical) tracing of the cycles in the field. The most prominent and excellent traceable marker bed is the red silt of cycle 50 even though it is not included in the lithological column of LY.

Two intervals can be distinguished, a lower interval (cycles 55-60) characterised by regular cycles with thick and distinct carbonate beds and an upper interval (cycles 61-64) consisting of reddish brown clay alternating with indistinct carbonate beds.

\subsection{Valdelosterreros II (VT-II)}

Subsection VT-II comprises cycles 46-68 and potential extra cycles 56A, 61A and 65A (Fig. 2). There are no exposures directly linking VT-II to LY. Geometric constructions indicate that the prominent red silt of cycle 50 is expected in the basal part of VT-II along Barranco El Mon, where indeed a similarly distinct red bed is found. The stratigraphic link is additionally based on characteristic cycle patterns recognised in subsections VT-II, LY and VT-I, such as the red clays of cycles 58 and 59. The VT-II trajectory starts in outcrops downstream of Barranco El Mon and continues upwards along the northern face of Valdelosterreros (see also Fig. 1).

Four distinct intervals can be recognised in VTII. The lower interval (cycles 46-50) comprises thick and clay-rich cycles and indistinct carbonates. In the second interval (cycles 51-59) regular cycles dominate while in the third interval, between cycles 61 and 64, thick cycles of dark grey or reddish brown clays with poorly developed carbonate beds occur. Regular cycles and well-developed carbonates reappear again in the upper interval of VT-II, between cycles 64 and 68 (Fig. 4).

\subsection{Valdelosterreros overlap (VTO)}

Subsection VTO comprises cycles 66-82 and a potential extra cycle 78A (Fig. 2). This subsection is situated close and opposite to VT-II and there- 
fore, in combination with continuous exposures in between the two subsections, allows an easy recognition of the characteristic cycle pattern.

Subsection VTO is characterised by regular and well-developed cycles (cycles 66-78) while the more reddish upper part (cycles 79-82) comprises poorly developed cycles with indistinct carbonate beds. The average cycle thickness in VTO reaches $1.3 \mathrm{~m}$.

\subsection{Valdelosterreros III (VT-III)}

The stratigraphically youngest subsection VTIII contains cycles $78-91$ and the potential extra cycles 78A, 82A, 84A, 87A and 90A (Fig. 2). The absence of continuous exposures hinders a direct and straightforward correlation between VTO and VT-III. Nevertheless, the white and distinct carbonate of cycles 78-79 and the overlying, alternating cycles of green and reddish brown clays in VTO are also recognised in VT-III. The short distance between the subsections and the (inferred) absence of faults excludes any other possible correlation.

VT-III can be subdivided into three distinct intervals. The lower interval comprises the light coloured cycles 78 and 79 with their distinct white carbonate beds. The next interval is characterised by an alternation of green and reddish to brown clays and by a gradual but notable increase in red colouring. The upper interval (cycles 85-91) comprises grey to brown clays alternating with light grey carbonate-rich clays while towards the top more distinct carbonate beds occur.

\section{The Orera Composite Section and cycle hierarchy}

Sedimentary cycles are not equally distinct in (overlapping parts of) subsections due to lateral facies changes and varying quality (weathering) of exposure. For a detailed study of the cyclostratigraphy, we selected only those (overlapping) parts of subsections in which the cyclicity is most prominently present, thus excluding parts in which the sedimentary cycle pattern are less obvious and, as a consequence, difficult to interpret. This optimi- sation can be achieved by using cyclostratigraphic correlations between subsections based on the lateral consistency of characteristic cycle patterns. This approach allows to select the most suitable intervals and to construct an Orera Composite Section (OCS) in which the 'ideal' succession of the cycles is depicted. This OCS is based on the following intervals from the individual subsections (Fig. 2): cycles $1-4$ from OB; 5-18 from CM; 19-27 from ORE; 28-48 from VT-I; 4967 from VT-II; 68-78A from VTO and 80-91 from VT-III. Altogether, the OCS comprises 91 cycles and 19 'A'-denoted cycles.

\subsection{Cycle hierarchy}

Visual changes in lithology allow us to distinguish two different scales or types of cyclicity in the OCS, the basic small-scale and the large-scale cycles. Apart from the small- and large-scale cycles, two other less distinct types of cyclicity of intermediate scale can also be recognised. The different scales of cycles are described in decreasing order of prominence in the field.

The basic small-scale cycles are the most prominent type of cyclicity. Basic cycles are characterised by an alternation of white carbonate beds and red or grey coloured clays. The average cycle thickness measures $1.6 \mathrm{~m}$, while the thickness of individual cycles may vary between 1.3 and $2 \mathrm{~m}$. Basic cycles are often thicker but with poorly developed carbonate beds in clay-rich intervals. Generally, an overall upward decrease in cycle thickness occurs towards the top part of the OCS.

The second type of cyclicity pattern occurs on a much larger scale and is termed the large-scale cycles. It consists of an alternation of relatively carbonate-rich intervals with regular and well-developed basic cycles and carbonate-poor (clayrich) intervals in which basic cycles are less distinct and regular. Typically, carbonate-rich intervals contain $10-11$ basic cycles while the clay-rich intervals contain seven or eight cycles. At least five large-scale alternations of carbonate-poor (clay-rich) and carbonate-rich intervals can be recognised in the OCS (Fig. 2). See also Fig. 3B.

Within the large-scale cycles two sedimentary cycles of intermediate scale can be recognised. Al- 
ternating thin-thick patterns of carbonate beds in successive basic small-scale cycles are observed in cycles 13-20 and in particular between cycles 28 and 48 (Fig. 3A). In the upper part of the OCS, between cycle 66 and 76, two bundles of five to six basic small-scale cycles can be identified (Fig. 3B). Clusters of this type of cyclicity are also present in the lower part of OCS, between cycles 1 and 13 .

Clearly, the different scales of superimposed sedimentary cycles in the OCS display a well-defined hierarchy. This hierarchy strongly resembles the cycle hierarchy observed in deep marine successions of late Neogene age in the Mediterranean, suggesting that it is caused by astronomically induced climate oscillation. The correlation of the magnetostratigraphy of the OCS to the GPTS must provide the time control necessary to test this working hypothesis.

\section{Magnetostratigraphy}

We used magnetostratigraphy to verify the cyclostratigraphic correlations and to construct a composite magnetostratigraphic record for the OCS. For an accurate and reliable dating highresolution sampling is required. Therefore, subsections were sampled with an overlap of at least two sedimentary cycles. From each sedimentary cycle four levels were sampled at an average distance of $40 \mathrm{~cm}$. Per sampling level two cores were drilled and oriented for palaeomagnetic analyses. In all subsections, the weathered surface was removed to drill in fresh sediments. Drilling was performed using an electric drill driven by a portable generator with water as a coolant.

The natural remanent magnetisation (NRM) of at least one sample per sampling level was thermally demagnetised in a laboratory-built shielded furnace and measured on a $2 \mathrm{G}$ Enterprises (RF or DC) SQUID magnetometer. Thermal demagnetisation was performed by step-wise temperature increments of $30-50^{\circ} \mathrm{C}$. Selected samples from different lithologies were subjected to isothermal remanent remagnetisation (IRM) acquisition. A PM-4 pulse magnetiser was used to acquire an IRM up to $2.0 \mathrm{~T}$, which was subsequently thermally demagnetised.

\subsection{Thermal demagnetisation}

Thermal demagnetisation diagrams show different types of demagnetisation, which appear to have a relationship with lithology. Good quality demagnetisation diagrams are mostly related to clays, whereas poor quality demagnetisations with low NRM intensities are often related to carbonate-rich lithologies. Thermal demagnetisation of the NRM and IRM of several samples from various lithologies enabled us to determine the magnetic properties of the samples and to distinguish the primary and secondary components. Based on these results, we divided the samples into four groups (Fig. 4).

Group A: Group A type of magnetic behaviour is typical for clay-rich sediments and most prominent in the red clays. Rare samples of this type occur in carbonate-rich lithologies.

Thermal demagnetisation of this group is characterised by a linear decay of the NRM to temperatures of $690^{\circ} \mathrm{C}$ (Fig. 4). The intensity of the NRM varies between 100 and $5000 \mu \mathrm{A} / \mathrm{m}$. In the demagnetisation diagrams we recognise, apart from a small viscous and randomly oriented component removed at a temperature of $100^{\circ} \mathrm{C}$, a component which is removed at temperatures between 100 and $200^{\circ} \mathrm{C}$. This component seems to have a present-day direction, probably caused by weathering. Two more obvious components can be recognised, one removed at temperatures between 520 and $570^{\circ} \mathrm{C}$ and another component removed at $690^{\circ} \mathrm{C}$.

IRM acquisition shows a rapid increase at low magnetic fields while no saturation occurs at $2.0 \mathrm{~T}$. Thermal demagnetisation of IRM in the two orthogonal axes shows the presence of two components with maximum unblocking temperatures of 570 and $690^{\circ} \mathrm{C}$, respectively. This implies that the magnetic carrier of the first, low-temperature, component is magnetite while the second, high-temperature, component is carried by haematite. Samples of both normal and reversed polarities display the above-described characteristics.

Group B: This group encompasses a variety of lithologies of reddish brown, grey and carbonaterich clays. The NRM intensities of this group are 


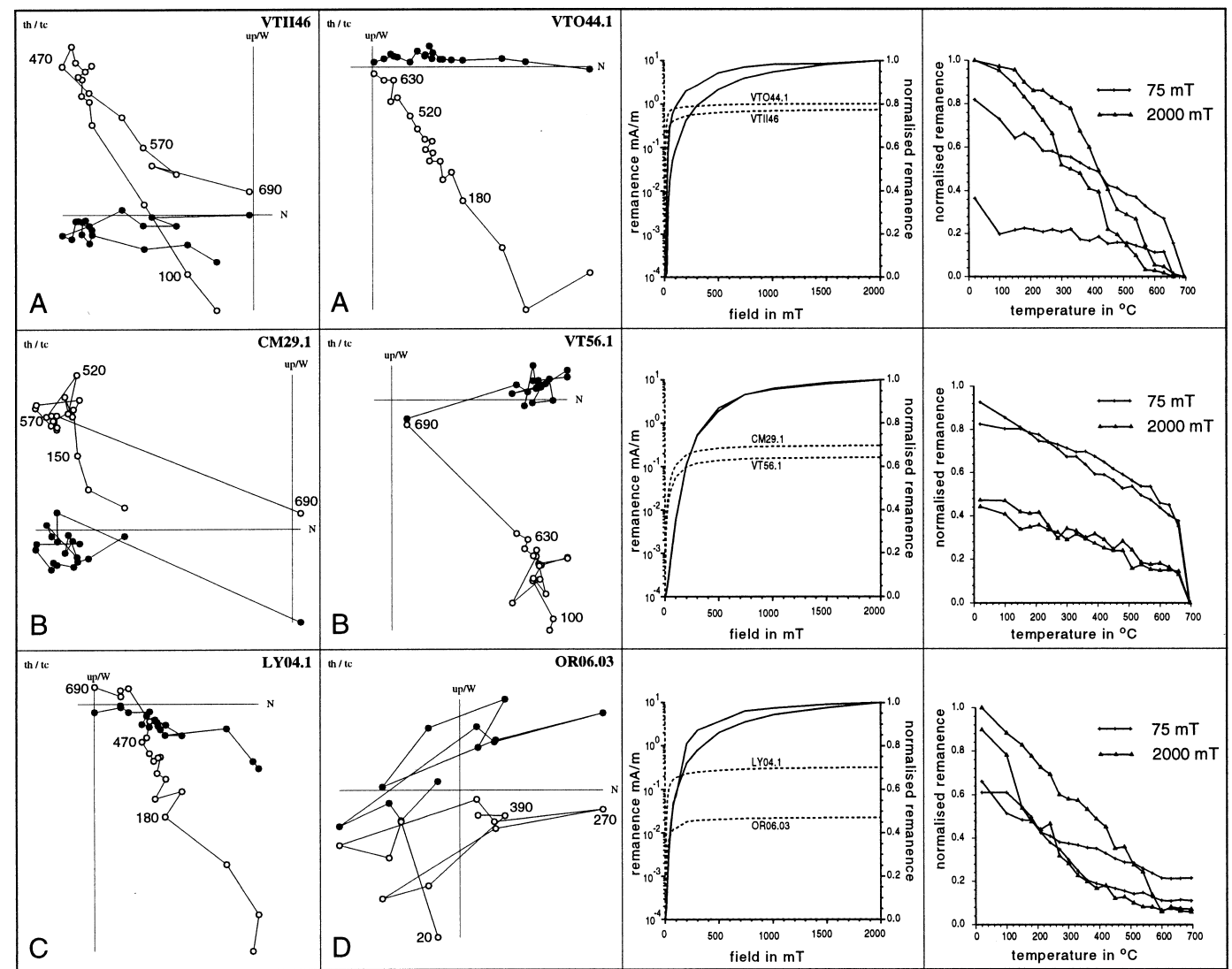

Fig. 4. Thermal demagnetisation and IRM acquisition diagrams of selected samples from groups A, B, C, and D (see text for details) of various subsections. In the IRM thermal demagnetisation diagram (rightmost) dashed lines correspond to samples VTII46, CM29.1 and LY04.1, respectively.

relatively moderate to low ranging between 100 and $3000 \mu \mathrm{A} / \mathrm{m}$. Apart from the small viscous and random oriented component, the most obvious characteristic of the thermal demagnetisation diagrams of group $\mathrm{B}$ is clustering of the NRM component up to $600^{\circ} \mathrm{C}$. Above this temperature, the NRM intensity decreases rapidly towards the origin upon heating to $690^{\circ} \mathrm{C}$ (Fig. 4).

Compared with group A, the IRM acquisition shows a relatively slow increase of the IRM in low magnetic fields. Thermal demagnetisation of the IRM reveals, for both orthogonal axes, a maximum unblocking temperature at $690^{\circ} \mathrm{C}$. We thus infer that the predominant magnetic carrier for this group is haematite.

All the demagnetisation characteristics are present in both reverse and normal polarities.
Group C: A few samples of various types of lithology fall into this group. NRM intensities are moderate to low varying between 100 and $1000 \mu \mathrm{A} / \mathrm{m}$. The thermal demagnetisation diagrams mostly display a linear decay but pass the origin hampering a reliable interpretation of the polarity signal (Fig. 4). IRM acquisition displays characteristics which differ from the group A type of demagnetisation, but imply that both magnetite and haematite determine the rock magnetic components.

Group D: Carbonates and carbonate-rich grey clays, of the transitional parts of carbonate beds, are the most dominant lithologies of this group. The NRM intensity is relatively low $(<100 \mu \mathrm{A} / \mathrm{m})$ and demagnetisation diagrams show a, viscous, scattering of the NRM component (Fig. 4). The 


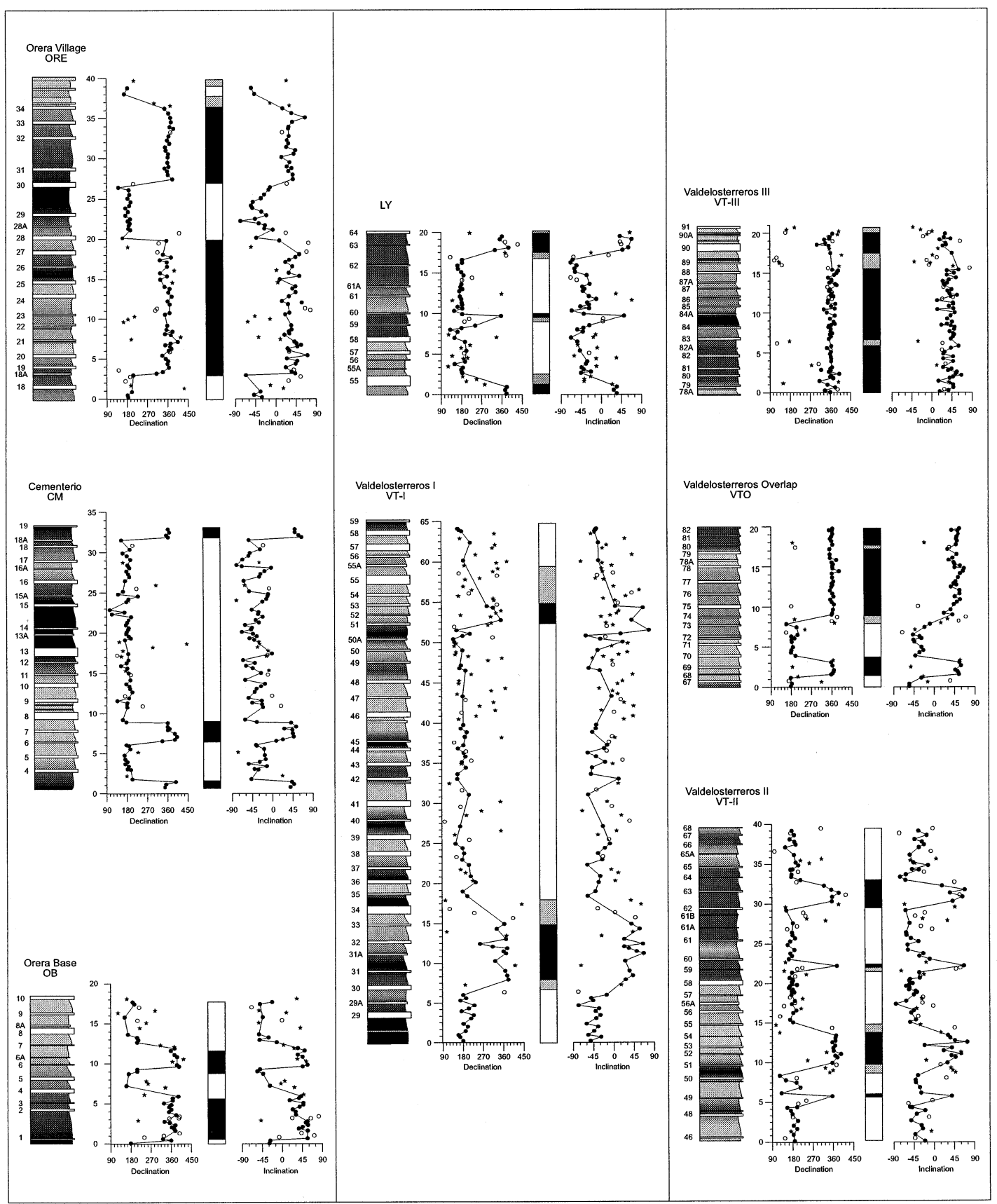

Fig. 5. Polarity zones, cycles and lithological columns of subsections OB, CM, ORE, VT-I, LY, VT-II, VTO and VT-III. Solid dots represent reliable directions of group A and B demagnetisation types. Open circles represent low intensity samples with less reliable directions of group $\mathrm{C}$ type of demagnetisation. Asterisks correspond to non-interpretable samples of group $\mathrm{D}$ demagnetisation. The black signal line connects only the reliable (solid dots) directions. In the polarity column, black denotes normal and white reversed polarity. Grey shaded zones represent uncertain polarity. Cycle numbers are indicated along the lithological columns. 
polarity of these samples can therefore not be interpreted.

Based on the results of rock magnetic analyses, the NRM of group A and B types of demagnetisation is interpreted to be the characteristic remanent magnetisation (ChRM). This ChRM is removed at a temperature of $690^{\circ} \mathrm{C}$ indicating that the high-temperature component is carried by haematite. The orientation of the ChRM can be reliably determined in the demagnetisation diagrams of both groups and is of either normal or reversed polarity. All these results imply that the ChRM is the primary component. In contrast, due to low NRM intensity or poor quality of the demagnetisation diagrams no reliable characteristic component, and thus also no primary component, could be determined for samples from groups C or D.

\subsection{The composite magnetostratigraphic record}

The magnetostratigraphy of all the studied subsections is straightforward (Fig. 5) although some parts of the subsections lack a clear polarity signal. Generally, from base to top of the successive subsections, the thermal demagnetisation character is dominated by group A and, to a much lesser extent, by group B type demagnetisation. In the central part, mainly in subsection VT-I, an increase of group D type demagnetisation occurs. Nevertheless, intervening samples with good signals have proven to be sufficient for a convincing interpretation of the overall polarity signal in subsection VT-I, and in all other intervals of the studied subsections.

The magnetostratigraphic correlations between the subsections depicted in Fig. 6 agree well with the cyclostratigraphic, bed-to-bed, correlation. No unusual discrepancies between the two stratigraphic correlation procedures are observed. Polarity zones registered in cycles of one subsection are confirmed in the same cycles of the (partially) overlapping other subsection. This enables us to define the uncertain or unclear polarities present in some subsections. If a polarity reversal occurs in the clay part of a cycle, with group A or B demagnetisation characteristics, we can determine the polarity within a precision of one cycle. This is not the case when a reversal occurs around carbonate beds with group $\mathrm{D}$ demagnetisation characteristics. The location of the reversal boundary may then vary within one cycle.

Altogether, the composite magnetostratigraphic record of Orera reveals nine reversed and 10 normal intervals, including a short normal event in cycle 59 (Figs. 5 and 6 ). The nine normal polarity intervals encompass, from top to base, the following cycles. The first long normal polarity interval is registered in cycles 73-90. The second and third in cycles 68-69 and 62-63. A fourth, very short normal interval, is found in cycle 59. The fifth, sixth, seventh and eighth are found in cycles 50 $53,30-33,18 \frac{1}{2}-26$ and $5 \frac{1}{2}-7$ respectively. Finally, the ninth normal interval is recorded in cycles $1-3$.

One of the most striking features of the Orera magnetostratigraphy is the presence of several short polarity intervals. Short normal intervals are found in cycles 62-63 (subsection VT-II) and in cycle 59 of subsections LY and VT-II (Figs. 5 and 6). Another very short normal event, and only found in one sample, is found in cycle 49 (subsection VT-II). Possible short reversed events are found in cycle $82 \mathrm{~A}$ and between cycles 88 and 90, all of subsection VT-III (Figs. 5 and 6). However, due to poor demagnetisation results we could not reliably confirm the polarity of the latter two events.

Additional samples from these (and other) levels were demagnetised to check the interpreted polarity. The results confirmed our earlier findings.

\section{Correlation with GPTS}

Samples suitable for determining the biostratigraphic age of the succession have not been obtained from the OCS itself. Small mammal biostratigraphic data from the area surrounding Orera nevertheless provide a reliable first-order age estimate for the OCS. Assemblages recovered from a nearby sepiolite mine (exploited by MYTA) were of late Aragonian age [22] corresponding to an age between 11.1 and $13.8 \mathrm{Ma}$ according to Daams et al. [23]. This also holds 
for a site recovered near the village of Miedes, south of Orera (Daams, personal communication, 1998). Both sites are stratigraphically below the base of the OCS if we take the bedding plane orientation near Miedes and the position of the MYTA mine locality into account.

Starting from the biostratigraphic age estimates, the magnetostratigraphy of the OCS can be calibrated unambiguously to the GPTS of
CK95 [24] (Fig. 6). This calibration shows that all polarity (sub)chrons in CK95 are also recorded in the OCS magnetostratigraphy. The base of the section corresponds to chron C5Ar.2n (o) and the top to C5n.2n (o). Extrapolation of the sedimentation rate shows that Orera covers a time interval of slightly more than $2 \mathrm{My}$, i.e. from 10.7 to 12.8 Ma. By plotting the stratigraphic thickness versus the calibrated GPTS ages (inset graph in Fig. 6)
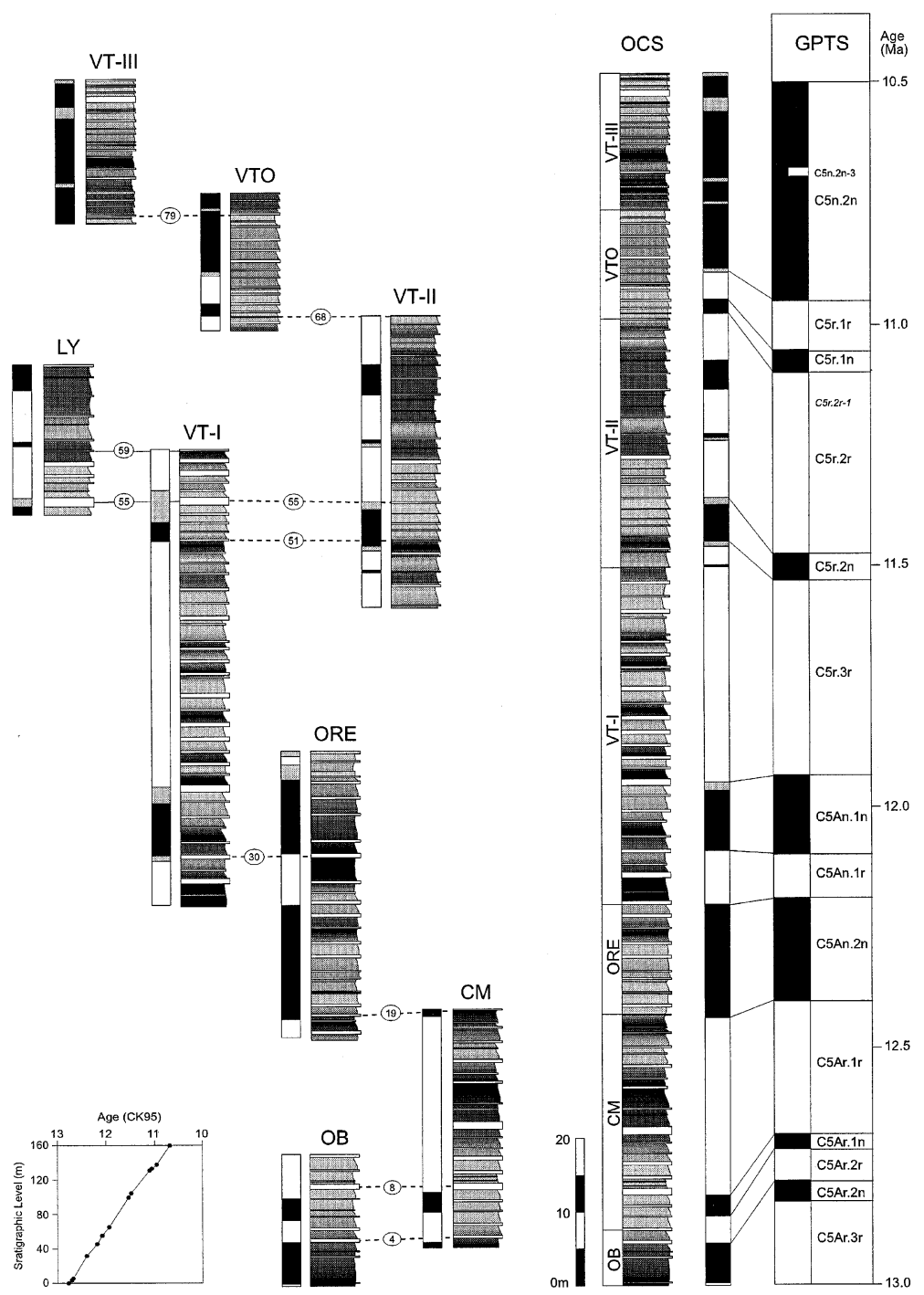

Fig. 6. Cyclostratigraphic and magnetostratigraphic correlations between subsections, and correlation of the OCS to the GPTS. Solid lines between OCS and GPTS connect (interpretative) concomitant polarity boundaries. See Fig. 2 for legend. The inset diagram illustrates the changes in accumulation rates through time (according to the GPST calibration points from CK95). Note the more or less similar slopes between subsequent time intervals. 
we observe that the accumulation rate in successive time intervals is more or less constant except for a short interval between 10.949 and $11.099 \mathrm{Ma}$ where the accumulation rate slightly decreases. Nevertheless, we conclude that the correlation of the magnetostratigraphy of the OCS to the GPTS allows for the interpretation depicted in Fig. 6.

The OCS magnetostratigraphy revealed the presence of two and possibly three extra normal polarity intervals that are not present in CK95 (Fig. 6). Short polarity events with a duration shorter than $30000 \mathrm{yr}$ are not well resolved in marine magnetic anomaly profiles. Nevertheless, Cande and Kent [25] detected some of these events, which they termed cryptochrons, in high spreading rate profiles from the Pacific. Apart from confirming cryptochrons previously identified by Cande and Kent [25], Schneider [26] identified several additional short polarity intervals of late Miocene age in the high-quality magnetostratigraphic records from ODP Leg 138 sites. The oldest new cryptochron of normal polarity was recorded at one Site 845 in the reversed polarity interval that corresponds to C5r.2r. This cryptochron, termed C5r.2r-1 by Schneider, had a duration of $26000 \mathrm{yr}$ and an age of 11.073 Ma according to the earlier GPTS CK92 [25]. This age will increase by approximately $110000 \mathrm{yr}$, to 11.18 Ma, if CK95 is used.

Linear interpolation of the sedimentation rate calculated between C5n.2n (o) and C5r.2n (y) (ages according to CK95) in the OCS results in an age of $11.186 \mathrm{Ma}$ for the normal polarity interval in cycles $62-63$ and a duration of $\sim 45000$ yr. These values are very similar to the ages of cryptochron C5r.2r-1, first recorded by Schneider in ODP Leg 138 Site 845. The other, very short normal polarity recorded in cycle 59 in subsections VT-II and LY has an age of $\sim 11.25 \mathrm{Ma}$ of and a duration of about $10000 \mathrm{yr}$. This event has not been observed in ODP Leg 138 sites and its existence has to await independent confirmation from other records. The possible third (extra) normal polarity interval, in cycle 49 , has been recorded in one sample only.

The two possible reverse intervals in OCS are recorded in cycle $82 \mathrm{~A}$ and between cycles 88 and 90 (in subsection VT-III). The latter event is esti- mated to have an age of $10.8 \mathrm{Ma}$ and probably corresponds to cryptochron C5n.2n-3. Further detailed palaeo- and rock magnetic analyses are necessary to confirm the presence of these events.

The magnetostratigraphic calibration to CK95 results in an average periodicity of $23000 \mathrm{yr}$ for the basic small-scale cycles in the OCS. This periodicity is reduced to $19000 \mathrm{yr}$ if the potential extra, 'A' denoted, cycles are taken into account as well. Both outcomes provide strong evidence that the basic cycles are related to precession-controlled variations in regional climate and, hence, that they have an orbital origin. Accepting a precessional origin for the basic small-scale cycles, the intermediate-scale and large-scale cycles in the Orera cycle hierarchy can be interpreted in terms of an astronomical control as well. In that case, the repetitive occurrence of the carbonatepoor intervals of the large-scale cycle will correspond to the $400000 \mathrm{yr}$ eccentricity cycle, while the intermediate-scale cycle will correspond to the $100000 \mathrm{yr}$ eccentricity and the precession-obliquity interference.

Clearly, a more rigorous, statistical analysis of quantitative (proxy) records is needed to provide definitive proof for the astronomical origin of the cyclicity and to understand the external forcing of the cycle hierarchy in the OCS. For the OCS offers a unique opportunity for understanding the climatic link between continental and marine sequences, and for extending the astronomical polarity time scale into the middle Miocene.

\section{Acknowledgements}

We are very grateful to have enjoyed pleasant fieldwork and discussions with Prof. Dr R. Daams and Dr M. Hoyos. Sadly, both passed away during the final writing of the manuscript. Prof. Dr C.E. Langereis and Prof. Dr J.E. Meulenkamp are thanked for their critical comments. Many thanks to S. Ernst, A. Blommendal, L. Pronk, A. Ockx and Y. Beukers for field (sampling) assistance. We also thank Dr P. Olsen and Prof. Dr Steininger for reviewing the manuscript. This research was supported by the Netherlands Geosciences Foundation (ALW) with finan- 
cial aid from the Netherlands Organisation for Scientific Research (NWO). The work was carried out in the program of the Netherlands Research School of Sedimentary Geology (NSG).[R $\boldsymbol{V}$ ]

\section{References}

[1] N.J. Shackleton, A. Berger, W.R. Peltier, An alternative astronomical calibration of the lower Pleistocene time scale based on ODP site 667, Trans. R. Soc. Edinburgh E.S. 81 (1990) 251-261.

[2] N.J. Shackleton, S. Crowhurst, T. Hagelberg, N.G. Pisias, D.A. Schneider, A new late Neogene time scale: Application to Leg 138 sites, Proc. Ocean Drill. Prog. Sci. Results 138 (1995) 73-101.

[3] F.J. Hilgen, Extension of the astronomically calibrated (polarity) time scale to the Miocene/Pliocene boundary, Earth Planet. Sci. Lett. 107 (1991) 349-368.

[4] R. Tiedemann, M. Sarnthein, N.J. Shackleton, Astronomic timescale for the Pliocene Atlantic $\delta^{18} \mathrm{O}$ and dust flux records of Ocean Drilling Program site 659, Paleoceanography 9 (1994) 619-638.

[5] F.J. Hilgen, W. Krijgsman, C.G. Langereis, L.J. Lourens, A. Santarelli, W.J. Zachariasse, Extending the astronomical (polarity) time scale into the Miocene, Earth Planet. Sci. Lett. 136 (1995) 495-510.

[6] N.J. Shackleton, S. Crowhurst, Sediment fluxes based on an orbitally tuned time scale $5 \mathrm{Ma}$ to $14 \mathrm{Ma}$, Site 926, Proc. Ocean Drill. Prog. Sci. Results 154 (1997) 69-82.

[7] W. Krijgsman, F.J. Hilgen, I. Raffi, F.J. Sierro, D.S. Wilson, Messinian astrochronolgy: the solution for an old problem, Nature 400 (1999) 652-655.

[8] L.J. Lourens, F.J. Hilgen, L. Gudjonsson, W.J. Zachariasse, Late Pliocene to Early Pleistocene astronomically forced sea surface productivity and temperature variations in the Mediterranean, Mar. Micropaleontol. 19 (1992) 4978.

[9] W.B. Bradley, The varves and climate of the Green River epoch, US Geol. Surv. Prof. Paper 158 (1929) 87-110.

[10] F.B. Van Houten, Cyclic lacustrine sedimentation, Upper Triassic Lockatong Formation, central New Jersey and adjacent Pennsylvania, in: O.F. Mermaid (Ed.), Symposium on Cyclic Sedimentation, Kans. Geol. Surv. Bull. 169 (1964) 497-531.

[11] P.E. Olsen, D.V. Kent, Milankovitch climate forcing in the tropics of Pangea during the Late Triassic, Palaeogeogr. Palaeoclimatol. Palaeoecol. 122 (1996) 1-26.

[12] P.E. Olsen, D.V. Kent, B. Cornet, W.K. White, R.W. Schlische, High-resolution stratigraphy of the Newark rift basin (early Mesozoic, eastern North America), Geol. Soc. Am. Bull. 108 (1996) 40-77.

[13] W. Krijgsman, C.G. Langereis, R. Daams, A.J. Van der Meulen, Magnetostratigraphic dating of the middle Mio- cene climate change in the continental deposits of the Aragonian type area in the Calatayud-Teruel basin (Central Spain), Earth Planet. Sci. Lett. 128 (1994) 513526.

[14] W. Krijgsman, W. Delahaije, C.G. Langereis, P.L. de Boer, Cyclicity and NRM acquisition in the Armantes section (Miocene, Spain): Potential for an astronomical polarity time scale for the continental record, Geophys. Res. Lett. 24 (1997) 1027-1030.

[15] N. Van Vugt, J. Steenbrink, C.G. Langereis, F.J. Hilgen, J.E. Meulenkamp, Magnetostratigraphy-based astronomical tuning of the early Pliocene lacustrine sediments of Ptolemais (NW Greece) and bed-to-bed correlation with the marine record, Earth Planet. Sci. Lett. 64 (1998) 535 551.

[16] J. Steenbrink, N. Van Vugt, F.J. Hilgen, J.R. Wijbrans, J.E. Meulenkamp, Sedimentary cycles and volcanic ash beds in the lower Pliocene lacustrine succession of Ptolemais (NW Greece): discrepancy between 40Ar/39Ar and astronomical ages, Palaeogeogr. Palaeoclimatol. Palaeoecol. (1999) in press.

[17] P. Anadón, E. Moissenet, in: P.F. Friend, C.J. Dabrio (Eds.), Tertiary Basins of Spain: the Stratigraphic Record of Crustal Kinematics, 1996, pp. 68-76.

[18] M. Julivert, Observaciones sobre la tectónica de la depresión de Calatayud Arraona, 1954, pp. 1-18.

[19] A. Marín, Sondeos de investigación de sales potásicas. Boletín de Sondeos, T. III. Istituto Geológico y Minero de España, Madrid.

[20] E. Sanz-Rubio, Análisis de los sistemas deposicionales carbonáticos y evaporíticos del Neógeno de la Cuenca de Calatayud (provincia de Zaragoza), PhD thesis, Universidad Complutense, Madrid, 1999.

[21] M. Hoyos, N. López Martínez, Iberic depression, in: Steininger et al. (Eds.), Neogene of the Mediterranean Tethys and Paratethys: Stratigraphic Correlations Tables and Sediment Distribution Maps, International Geological Correlation Program (1985), Project 25, Vol. 1.

[22] J.A. Andrés, J.I. Canudo, G. Cuenca, C. Laplana, Los vertebrados del Terciario continental de la mina de sepiolita de Mara (Provincia de Zaragoza), VIII Jornadas de Paleontologia, Resumenes, 1992.

[23] R. Daams, A.J. Van der Meulen, M.A. Alvarez-Sierra, P. Paláez-Campomanes, W. Krijgsman, Aragonian stratigraphy reconsiderd, Earth Planet. Sci. Lett. 164 (1999) 287 294.

[24] S.C. Cande, D.V. Kent, Revised calibration of the geomagnetic polarity time scale for the late Cretaceous and Cenozoic, J. Geophys. Res. 100 (1995) 6093-6095.

[25] S.C. Cande, D.V. Kent, A new geomagnetic polarity time scale for the Late Cretaceous and Cenozoic, J. Geophys. Res. 97 (1992) 13917-13951.

[26] D.A. Schneider, Paleomagnetism of some Leg 138 sediments: Detailing Miocene magnetostratigraphy, Proc. Ocean Drill. Prog. Sci. Results 138 (1995) 59-72. 